\title{
Coupled Effects of Hydrophilic Nano Silica Oxide and Anatase Nano Titanium Oxide on Strengths of Oilwell Cement
}

\author{
Petro E Mabeyo ${ }^{1 *}$ and Jun $\mathrm{Gu}^{2 *}$ \\ ${ }^{1}$ Department of Chemistry, Faculty of Science, Dar es Salaam University College of Education, $P$. \\ O. Box 2329, Dar es Salaam, Tanzania \\ ${ }^{2}$ Department of Petroleum Engineering, Faculty of Earth Resources, China University of \\ Geosciences, Wuhan 430074, China \\ *Corresponding author: mabeyo.petro@duce.ac.tz (Mabeyo); \\ Co-author:gujun@cug.edu.cn $(\mathrm{Gu})$
}

Received 9 Nov 2020, Revised 27 Apr 2021, Accepted 28 Apr 2021, Published May 2021

DOI: https://dx.doi.org/10.4314/tjs.v47i2.13

\begin{abstract}
The life of oilwells depends on the stability of cement sheath and bond strength with the formation and casing. Extreme subsurface conditions cause substantial stresses on the cement sheath resulting in a serious impact on well integrity. The recommended API cement for oilwell fails to provide the required durability of the cemented well due to such conditions. Supplementary cementitious materials such as nanoparticles are added to improve the cement for long-lasting zonal isolation. In this study, the compressive and shear bond strengths of oilwell cement containing nano- $\mathrm{SiO}_{2}$ and nano- $\mathrm{TiO}_{2}$ were studied at $80{ }^{\circ} \mathrm{C}$ for $3,7,14$, and 28 days of hydration. The XRD, TG, and DSC were used for the analysis of cement hydration products. The results revealed that both nano- $\mathrm{SiO}_{2}$ and nano- $\mathrm{TiO}_{2}$ increased strength evolution. A ternary system made with $2 \%$ nano- $\mathrm{SiO}_{2}$ and $2 \%$ nano- $\mathrm{TiO}_{2}$ improved compressive strength by 22.6 and $48.4 \%$, while the shear bond strength increased by 110.6 and 55\% at age of 3 days and 28 days, respectively, compared to their corresponding binary systems. Therefore, these results remark the potential of replacing an appropriate proportion of oilwell cement with coupled nano- $\mathrm{SiO}_{2}$ and nano- $\mathrm{TiO}_{2}$ to ensure cement sheath structure durability in the annular and long-lasting zonal isolation.
\end{abstract}

Keywords: Nano-silica, nano-titanium, compressive strength, shear bond strength, oilwell cement.

\section{Introduction}

In oil and gas well cementing, the cement slurry is filled outside the casing pipes ( $\mathrm{Li}$ et al. 2017). Thus, the sheath modification is required to maintain the well integrity behind the casing (Zeng et al. 2019) and provide longterm zonal isolation to ensure the safety and prevention of environmental problems (Jafariesfad et al. 2017). However, the variation of subsurface conditions such as temperature in the oilwell poses a challenge of degradation to the use of ordinary Portland cement that compromises the strength development
(Omosebi et al. 2017). Excessive temperature induces distortion which leads to the failure of cement to provide long-lasting sealing (Won et al. 2015). The poor performance in bottom wellbore conditions leads to costly repair operations, a reduction in production capacity, environmental disputes, and even loss of the well as the worst-case (Jimenez et al. 2016). Portland cement also suffers degradation when exposed to varying conditions such as aggressive fluids; this makes it not suitable for well cementing for the $\mathrm{CO}_{2}$-rich environment (Xu et al. 2019). Therefore, the failure under 
various conditions necessitates the use of other supplements along with cement.

Some of the supplements include nanosized materials (nanomaterials) with small sizes which range from $1 \mathrm{~nm}$ to $100 \mathrm{~nm}$ (Bera and Belhaj 2016). The small particles have a high surface-to-volume ratio that accounts for their high reactivity (Lau et al. 2017). Their inclusion in cement imparts functionality of the cement which leads to property enhancement (Ren et al. 2018). Some of the most reported nanomaterials which enhance cementitious properties are nano- $\mathrm{SiO}_{2}$, nano- $\mathrm{TiO}_{2}$, nano$\mathrm{Al}_{2} \mathrm{O}_{3}$, nano- $\mathrm{Fe}_{2} \mathrm{O}_{3}$ and carbon nano-tubes (Nazari and Riahi 2011, Khoshakhlagh et al. 2012, de Paula et al. 2014, Tzileroglou et al. 2017).

Nano- $\mathrm{SiO}_{2}$ and nano- $\mathrm{TiO}_{2}$ are given more attention due to their dominant advantages on the improvement of compressive strength at early as well as late age of cement hydration in concrete studies (Ren et al. 2018). The literature survey has confirmed that nano- $\mathrm{SiO}_{2}$ can be used as a lightener agent in oilwell cement due to its particle fineness. It further prevents strength retrogression/ degradation (Cestari et al. 2013). Nano- $\mathrm{SiO}_{2}$ acts as a nucleating agent, and therefore, quickens the hydration of cement by producing more calcium silicate hydrate (C-S-H) gel (Rai and Tiwari 2018) whose structure increases with nanoparticle content and hydration age (Stefanidou and Papayianni 2012). The presence of silica causes the formation of xonotlite, a stable phase of C-S-H gel. In addition to its high reactivity and nucleation ability, nano-SiO $\mathrm{S}_{2}$ reacts with the calcium hydroxide $(\mathrm{CH})$ product of cement hydration through a pozzolanic reaction. The reaction forms an additional fraction of C-S-H gel which contributes to cement strength development (de Sena Costa et al. 2017).

The use of nano- $\mathrm{TiO}_{2}$ along with cement is reported to increase the flexural strength of concrete (Nazari and Riahi 2010, Nazari and Riahi 2011, Jalal et al. 2013). Unlike nano$\mathrm{SiO}_{2}$, nano- $\mathrm{TiO}_{2}$ is not a pozzolanic material; its effects on cement performance are counted based on its high reactivity and inert filling effects. The addition of nano- $\mathrm{TiO}_{2}$ to cement accelerates the initial and final setting, decreases fluidity, promotes early hydration, and accelerates the formation and precipitation of hydration products (Ma et al. 2016). The dosage and amount of water can significantly affect the strength development of nano- $\mathrm{TiO}_{2}$ based cement. The work of Lee et al. (2013) in concrete has reported that compressive strength of cement made with higher $\mathrm{TiO}_{2}$ nanoparticle substitution (cured at $23{ }^{\circ} \mathrm{C}$ ) increases at lower water-to-solids ratio while remaining uncompromised when substitution is made up to $10 \% \mathrm{TiO}_{2}$ at higher water-to-solids ratio.

Several laboratory-based works have extended to study the synergism of nanoparticles or nanoparticles with other supplementary cementitious materials. ElGamal et al. (2017) reported the increase in compressive strength due to coupled carbon nano-tubes, nano- $\mathrm{SiO}_{2}$, and nano-metakaolin on oilwell cement properties at elevated water curing temperature of $90{ }^{\circ} \mathrm{C}$. Another study involves coupled nano-montmorillonite and nano- $\mathrm{TiO}_{2}$ with up to $1 \mathrm{wt} \%$ as an optimum percentage whereas the coupled effect of nanoparticles accelerated C-S-H gel formation while increasing the cement strength (SadeghiNik et al. 2017). Coupling of nano- $\mathrm{SiO}_{2}$ and nano- $\mathrm{TiO}_{2}$ has also been reported in concrete where both act as crystallization centers of $\mathrm{CH}$ as well as fillers in the space, reducing the crystal surface and improving the strength of the concrete. However, although both react with $\mathrm{CH}$, only nano- $\mathrm{SiO}_{2}$ produces $\mathrm{C}-\mathrm{S}-\mathrm{H}$ gel to enhance the early strength of the concrete (Ren et al. 2018). Based on the knowledge of the authors, there is scarce information about the synergistic effects of nanoparticles on the properties of oilwell cement. It is also observed that there are no detailed studies that concentrated on the shear bond strength at the cement-formation interface using coupled nanoparticles as cement admixtures.

Bond strength at the cement-formation as well as cement-casing is of paramount importance for the life of oilwells. De-bonding 
at the interface of formation-cement-casing due to the introduction of more loads in the well in the long term is a result of lower bond strength. The latter can allow the flow of formation fluids from zone to zone or the surface resulting in health and safety risks. Higher bond strength is therefore anticipated to prevent leakage paths at this boundary (Salehi et al. 2017, Hwang et al. 2018). The ability of the cement to prevent inter-layer communication is reflected by shear bond strengths of cement-to-formation and cementto-casing. Design of good slurry for oilwell cementing operations is crucial to avoid future problems and overspending, keeping in mind that cementing operation is one of the most important and expensive activities done in petroleum wells (Soares et al. 2015). Therefore, the application of nano-sized particles becomes economically beneficial, at least by projecting to hostile zones.

The current study, therefore, entailed using the coupled nano- $\mathrm{TiO}_{2}$ and nano- $\mathrm{SiO}_{2}$ to study their synergistic effects on oilwell cement's compressive and shear bond strengths. The strengths of the studied samples were significantly improved as compared to the reference Class $G$ oilwell cement with high sulfur resistant grade. The Coupled nano- $\mathrm{SiO}_{2}$ and nano- $\mathrm{TiO}_{2}$ can ensure cement sheath structure durability in the annular and longlasting zonal isolation. Therefore, the results propose a potential oilwell cement design that can prevent cement sheath failure, improved long-term zonal isolation, and thus well integrity of oilwells through the optimized admixture proportions.

\section{Materials and Methods: Experimental Program \\ Materials}

Materials applied in this study included: a high sulfur resistant commercial API Class G oilwell cement from Jiahua Enterprises Corp., (Sichuan China); hydrophilic nano-SiO ${ }_{2}$ (BRSP30) and anatase nano- $\mathrm{TiO}_{2}$ used as received for partial replacement of oilwell cement were supplied by Briture Co., Ltd (Hefei, Anhui, China). The chemical composition and physical properties of oilwell cement are presented in Table 1, while physical properties for nano$\mathrm{SiO}_{2}$ and nano- $\mathrm{TiO}_{2}$ are presented in Table 2 .

Table 1: Chemical composition and physical properties of OWC

\begin{tabular}{lccccccccccc}
\hline Component & $\mathrm{CaO}$ & $\mathrm{SiO}_{2}$ & $\mathrm{Fe}_{2} \mathrm{O}_{3}$ & $\mathrm{Al}_{2} \mathrm{O}_{3}$ & $\mathrm{SO}_{3}$ & $\mathrm{MgO}$ & $\mathrm{Na}_{2} \mathrm{O}$ & $\mathrm{K}_{2} \mathrm{O}$ & $\begin{array}{l}\mathrm{SSA} \\
\left(\mathrm{m}^{2} / \mathrm{kg}\right)\end{array}$ & $\begin{array}{l}\text { Density } \\
\left(\mathrm{g} / \mathrm{cm}^{3}\right)\end{array}$ & L.O.I \\
\hline $\mathrm{Wt}(\%)$ & 64.20 & 19.40 & 5.50 & 4.50 & 2.80 & 2.00 & 0.10 & 0.60 & 336.00 & 3.15 & 0.49 \\
\hline
\end{tabular}

Table 2: Physical properties of nanomaterial used

\begin{tabular}{lccccc}
\hline Nanomaterial & Abbreviation & Purity (\%) & $\begin{array}{c}\text { Average particle size } \\
(\mathrm{nm})\end{array}$ & $\begin{array}{c}\text { Specific surface area } \\
\left(\mathrm{m}^{2} / \mathrm{g}\right)\end{array}$ & $\mathrm{pH}$ \\
\hline Nanosilica & $\mathrm{nS}$ & 99.9 & 20 & 220 & 5.7 \\
Nanotitanium & $\mathrm{nT}$ & 99.9 & 10 & 160 & 6.8 \\
\hline
\end{tabular}

\section{Methods}

\section{Slurry preparation}

Cement slurry was prepared by adding 792 $\mathrm{g}$ of the solid mixture (cement, cement + nanomaterials) to $354 \mathrm{~mL}$ of water adhering to the API 10A (2002). The weighed amount of cement and admixtures (Tables 3-4) were hand mixed in a dry bowl using a clean spatula. The dispersant was dissolved into the mixing water and then mixing aqueous solution poured in the blender. The mixing was initiated slowly and then the cement admixture was added for 15 seconds while blending at a slow speed of $4 * 10^{3} \mathrm{rm}^{-1}$. The manual mixing was conducted for $30 \mathrm{sec}$ with the rubber spatula aiding to recover material sticking to the wall of the mixing container to ensure homogeneity. Then to finalize, the cover was placed on the mixing container and mixing was done at a high speed of $12 * 10^{3} \mathrm{rm}^{-1}$ for 35 seconds. 
Tanz. J. Sci. Vol. 47(2), 2021

Table 3: Composition of OWC pastes with nano- $\mathrm{SiO}_{2}$ and nano- $\mathrm{TiO}_{2}$

\begin{tabular}{|c|c|c|c|c|}
\hline Mixes & Abbreviation & $\mathrm{OWC}(\mathrm{g})$ & nano-SiO ${ }_{2}(\mathrm{~g})$ & $\begin{array}{l}\text { Water/Binder } \\
\text { ratio }\end{array}$ \\
\hline $100 \% \mathrm{OWC}$ & $\mathrm{nSO}$ & 792.00 & & 0.45 \\
\hline $99 \% \mathrm{OWC}+1 \%$ nano- $\mathrm{SiO}_{2}$ & $\mathrm{nS} 1$ & 784.08 & 7.92 & 0.45 \\
\hline $98 \% \mathrm{OWC}+2 \%$ nano- $\mathrm{SiO}_{2}$ & $\mathrm{nS} 2$ & 776.16 & 15.84 & 0.45 \\
\hline $97 \% \mathrm{OWC}+3 \%$ nano- $\mathrm{SiO}_{2}$ & $\mathrm{nS} 3$ & 768.24 & 23.76 & 0.45 \\
\hline $96 \% \mathrm{OWC}+4 \%$ nano- $\mathrm{SiO}_{2}$ & $\mathrm{nS} 4$ & 760.32 & 31.68 & 0.45 \\
\hline $99 \% \mathrm{OWC}+1 \%$ nano- $\mathrm{TiO}_{2}$ & nT1 & 784.08 & 7.92 & 0.45 \\
\hline $98 \% \mathrm{OWC}+2 \%$ nano- $\mathrm{TiO}_{2}$ & nT2 & 776.16 & 15.84 & 0.45 \\
\hline $97 \% \mathrm{OWC}+3 \%$ nano- $\mathrm{TiO}_{2}$ & nT3 & 768.24 & 23.76 & 0.45 \\
\hline $96 \% \mathrm{OWC}+4 \%$ nano- $\mathrm{TiO}_{2}$ & nT4 & 760.32 & 31.68 & 0.45 \\
\hline
\end{tabular}

Table 4: Composition of OWC pastes with coupled nano- $\mathrm{SiO}_{2}$ and nano- $\mathrm{TiO}_{2}$

\begin{tabular}{|c|c|c|c|c|c|}
\hline Mixes & Abbreviation & OWC (g) & $\begin{array}{l}\text { Nano- } \\
\mathrm{SiO}_{2}(\mathrm{~g})\end{array}$ & $\begin{array}{l}\text { Nano- } \mathrm{TiO}_{2} \\
(\mathrm{~g})\end{array}$ & $\begin{array}{l}\text { Water/ } \\
\text { Binder } \\
\text { ratio }\end{array}$ \\
\hline $\begin{array}{c}97 \% \text { OWC }+2 \% \text { nano- } \mathrm{SiO}_{2} \\
+1 \% \text { nano- }-\mathrm{TiO}_{2}\end{array}$ & nST3 & 768.24 & 15.84 & 7.92 & 0.45 \\
\hline $\begin{array}{c}96 \% \mathrm{OWC}+2 \% \text { nano- } \mathrm{SiO}_{2} \\
+2 \% \text { nano- } \mathrm{TiO}_{2}\end{array}$ & nST4 & 760.32 & 15.84 & 15.84 & 0.45 \\
\hline $\begin{array}{c}95 \% \mathrm{OWC}+2 \% \text { nano- } \mathrm{SiO}_{2} \\
+3 \% \text { nano- }-\mathrm{TiO}_{2}\end{array}$ & nST5 & 752.40 & 15.84 & 23.76 & 0.45 \\
\hline $\begin{array}{c}95 \% \text { OWC }+2 \% \text { nano }-\mathrm{SiO}_{2} \\
+4 \% \text { nano }-\mathrm{TiO}_{2}\end{array}$ & nST6 & 744.48 & 15.84 & 31.68 & 0.45 \\
\hline
\end{tabular}

\section{Strength evolution studies}

The study of compressive strength was done using the uniaxial compressive strength tester. Test samples with equal dimensions of 50 × $50 \mathrm{~mm}$ were made from previously prepared cement slurry and cured for $3,7,14$, and 28 days in a water bath set at a temperature of $80{ }^{\circ} \mathrm{C}$. The average values for three cured test samples for each of the cement mix were recorded in $\mathrm{MPa}$ according to the equation: $p=10 F / A$, where $p$ is compressive strength, $F$ is loading force $(\mathrm{kN}), A$ is the area of the cube acted by the loading force $\left(\mathrm{cm}^{2}\right)$ and 10 is the unit conversion factor.

Shear bond strength studies were done with the help of simulated wellbores (SWBs). Each of the SWBs was made from the mortar paste prepared by mixing $585 \mathrm{~g}$ of well-sorted sand, $215 \mathrm{~g}$ of building cement, and $70 \mathrm{~mL}$ of water. The procedures by $\mathrm{Gu}$ et al. (2012) were partly used. An adjustable PVC pipe with an internal diameter of $10 \mathrm{~cm}$ was filled with the mortar and subjected to compression on the pressure testing machine frame. The mortar was gradually compressed at a uniform rate of 2.5 $\mathrm{kN} / \mathrm{min}$ with the steely cylindrical indenter. Each of the SWBs was left to dry at room temperature for 3 days before removing the adjustable PVC pipe mold to separate from the prepared SWB. Then to simulate the mud cake formation, the dried SWBs were mounted on a glass plate with high-temperature butter to seal the base. Each of the sealed SWBs was injected with water-based drilling mud and left for about five hours to allow mud cake formation. Then the false mud cake was gradually removed with glass rods to simulate the activity of the bore until a dense mud cake formed. The prepared cement slurry with and without nano- $\mathrm{SiO}_{2}$ and nano- $\mathrm{TiO}_{2}$ were injected into the corresponding SWBs with a uniform thickness of mud cake put into the curing bath with the temperature set at $80{ }^{\circ} \mathrm{C}$ for $3,7,14$, and 28 days (Figure 1). 
Mabeyo and $\mathrm{Gu}$ - Coupled effects of hydrophilic nano-SiO${ }_{2}$ and anatase nano-TiO $\mathrm{T}_{2} \ldots$

The heights of all cured samples were measured before the push-out test was employed at the cement-formation interface. A hydraulic shear bond tester was used to test the shear bond strength. The test sample was placed between the force and the backing plate of the adjusted hydraulic press. A force head aided to press the hydrated cement sheath from the bore. Then, to determine the shear bond strength, the maximum force reached when the shear bond just breaks was recorded (Jadhav et al. 2017). The average of the three test samples for each curing time and every mix system was recorded for calculation of shear bond strength according to the equation, $p=10 F / \pi h D$ (Gu et al. 2012) where $p$ is shear bond strength (MPa), $F$ is the shear force at cement-formation interface $(\mathrm{kN}), h$ is the height of SWB $(\mathrm{cm})$, and $D$ is the inner diameter of SWB $(\mathrm{cm})$.

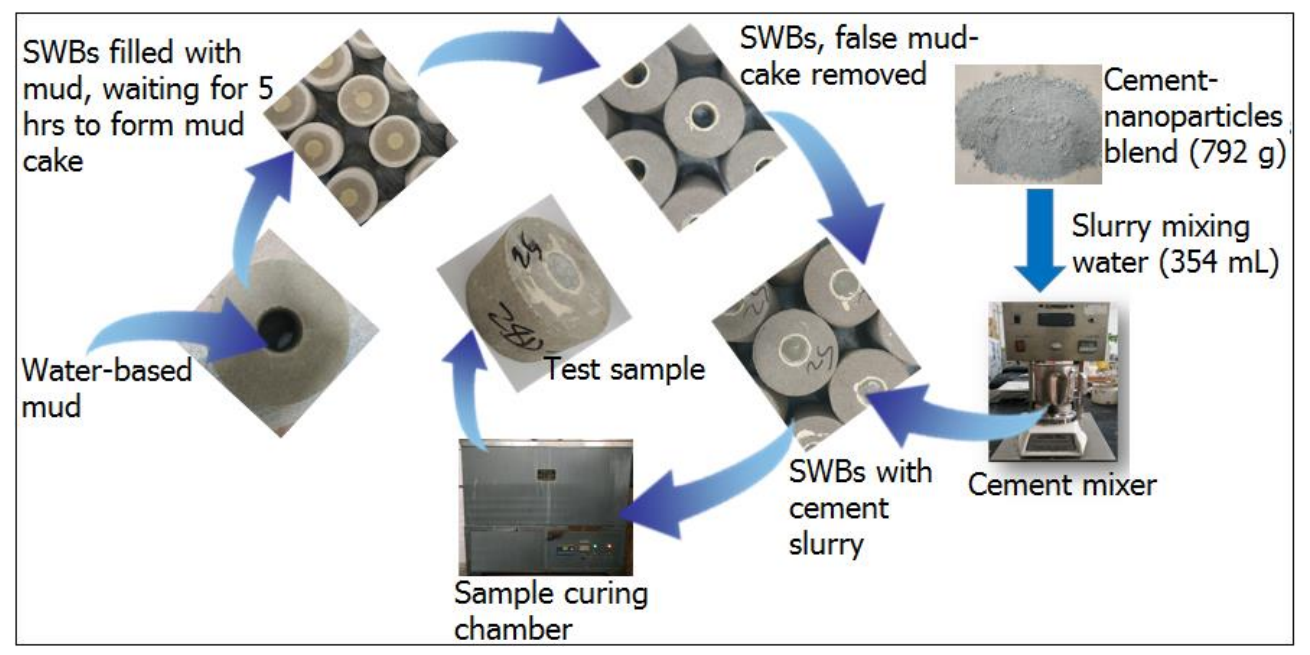

Figure 1: Summary of shear bond strength test sample preparation.

\section{XRD, TG and DSC studies}

The X-ray diffraction (XRD) was run on D8 Advance XRD (Bruker D8 Advance, Germany) equipped with a LynxEye detector, graphite- monochromatized $\mathrm{CuK} \alpha$ radiation source, and Ni-filter for the $\operatorname{CuK} \beta$. The radiations were generated at $40 \mathrm{kV}$ and $40 \mathrm{~mA}$. FT scanning was carried out at $2 \mathrm{~h}$ in a range of $5-90^{\circ}$, while the step size was $0.01^{\circ}$. Finely grounded dry samples (about $0.5 \mathrm{~g}$ each) were used to obtain the XRD patterns. X'Pert High Score Plus program was used for XRD raw data processing, pattern quantification, and identification. Thermo gravimetric-differential scanning calorimetry (TG-DSC) was run on the STA 409 PC model (NETZSCH Instruments Manufacturing Co., Ltd, Germany). The tests were performed by heating from $30{ }^{\circ} \mathrm{C}$ to 1000 ${ }^{\circ} \mathrm{C}$ at an increasing temperature rate of 20 ${ }^{\circ} \mathrm{C} /$ min under a $\mathrm{N}_{2}(\mathrm{~g})$ atmosphere at the flow rate of $50 \mathrm{~mL} / \mathrm{min}$. About $30 \mathrm{mg}$ powdered samples were subjected to heating for each system.

\section{Results and Discussion Compressive strength evolution}

The compressive strengths for reference samples, nano- $\mathrm{SiO}_{2}$, and nano- $\mathrm{TiO}_{2}$ binary systems are presented in Figure 2. The figure shows that the variations of compressive strength evolution for both cement systems with and without nanoparticles have the general trend of increasing with curing age. It was observed that the addition of nano- $\mathrm{SiO}_{2}$ (Figure 2a) influenced the strength evolution which had a limit on the content added especially at the age of 3 days to 7 days. Although all systems indicated higher strength than that of the reference, $\mathrm{nS} 0$, the difference between $\mathrm{nS} 0$ and $\mathrm{nS} 4$ at this age was small. 
This means the higher content of nano- $\mathrm{SiO}_{2}$ did not have a high contribution to strength evolution. The possible explanation of low strength contribution from a higher dosage can be attributed to aggregation as proposed by other studies (Ren et al. 2018). At the later age from 14 days to 28 days, the increase was due to the contribution of pozzolanic reaction.

The sample systems $\mathrm{nS} 2$ and $\mathrm{nS} 3$ showed a better contribution to strength evolution. This means were sufficient amounts to provide a nucleation site for the crystallization of $\mathrm{CH}$ and later pozzolanic reaction with the produced $\mathrm{CH}$ from cement hydration concurring with other reports (Beigi et al. 2013). The compressive strengths of $\mathrm{nS} 2$ and $\mathrm{nS} 3$ increased by $32.3 \%$ and $25.3 \%$ at 3 days, and $34.5 \%$ and $23.7 \%$ at 28 days of hydration, respectively, over $\mathrm{nS}$. This is evident that $2 \%$ nano- $\mathrm{SiO}_{2}$ is most significant for cement hydration, and thus strength evolution at an early age as well as later age.

As shown in Figure 2 (b), the results of incorporating nano- $\mathrm{TiO}_{2}$ into oilwell cement showed a general trend of increasing with hydration age. At 3 days and 7 days of hydration, nT1 showed the highest strength evolution compared to the rest. At the age of 14 and 28 days, the highest strength evolution was seen for the nT3 system. Thus, the increase in nano- $\mathrm{TiO}_{2}$ content was favorable to strength evolution at later hydration age as observed

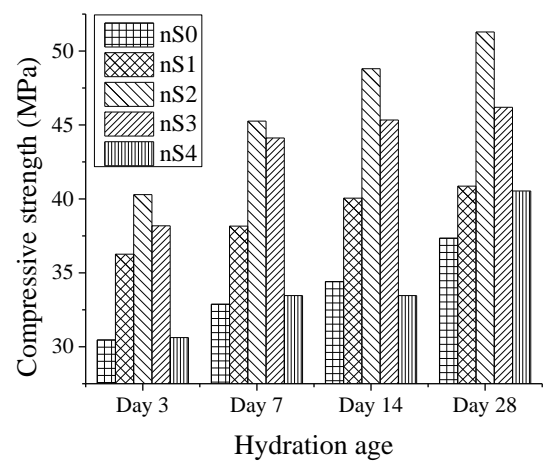

(a) from 14 days to 28 days of hydration where nT3 and nT4 showed high contribution to strength, while slight deceleration of the rate of hydration was observed for nT1 and remained almost the same for nT2. This means compressive strength increased with nano- $\mathrm{TiO}_{2}$ content at the later age of hydration. The possible reason attributed to the observation is because low nano- $\mathrm{TiO}_{2}$ was not sufficiently reacted with $\mathrm{CH}$ to add secondary long-chained $\mathrm{C}-\mathrm{S}-\mathrm{H}$ gel as nano-SiO${ }_{2}$ does. This observation is in agreement and contrary to some of the reported works in concrete. Some works reported low content to contribute to high strength evolution in concrete at an early age (Qing et al. 2007, Ren et al. 2018), while others reported higher content of nano- $\mathrm{TiO}_{2}$ to favor early strength development of cementitious systems (Jalal et al. 2013, Lee and Kurtis 2010). The present results concurred with the findings of the former works.

The contribution of nano- $\mathrm{TiO}_{2}$ on strength is based on the filler effect and the ability to provide more nucleation sites at a very early age of hydration. The nano- $\mathrm{TiO}_{2}$ content at a low dosage was suitable for the more nucleation sites at an early age which built up more hydration products at an early age while delaying the onset of diffusion-controlled hydration. When more hydration products are formed at an early age, cement expansion rather than shrinkage is favored.

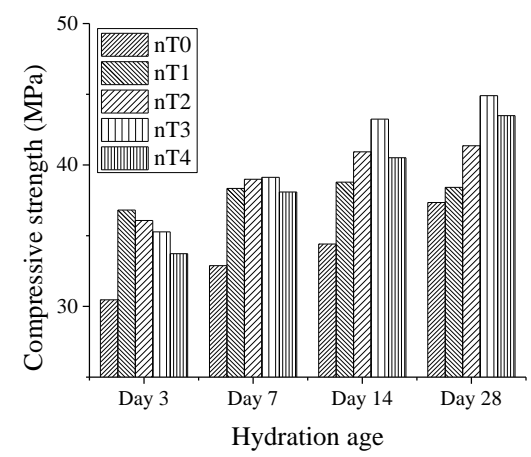

(b)

Figure 2: Compressive strength for control, nano- $\mathrm{SiO}_{2}$, and nano- $\mathrm{TiO}_{2}$ binary systems. 
Mabeyo and $\mathrm{Gu}$ - Coupled effects of hydrophilic nano-SiO $\mathrm{S}_{2}$ and anatase nano-TiO $\mathrm{T}_{2} \ldots$

Based on the different behaviors displayed by nano- $\mathrm{SiO}_{2}$ and nano- $\mathrm{TiO}_{2}$ in cement properties, their coupled effects were studied. Figure 3 presents the compressive strengths of the cement systems containing $2 \%$ nano- $\mathrm{SiO}_{2}$ (nS2) and varying amounts of nano- $\mathrm{TiO}_{2}$. The figure indicates that the ternary system improved the compressive strength of oilwell cement and increased with curing age. The coupling effect was more significant at the early age of hydration as compared to the later age. The figure shows that, at the age of 3 days, the compressive strength evolution was much higher for nST3 by 5.9 and $19.9 \%$ relative to the binary $\mathrm{nS} 2$ and $\mathrm{nT} 1$, respectively. This means the coupling serves more advantages for the nT1 binary system than $\mathrm{nS} 2$ at this age. Progressing with time the ternary system nST4 had an almost linear increase in strength evolution. From 14 days to 28 days, its contribution was systematically increasing such that more compressive strength was recorded. Compared to the respective binary systems nS2 and nT2, the ternary system nST4 had an increase of $4.35 \%$ for the nT2 system, while no increase for the nS2 system was observed.

As can be seen from the XRD, TG, and DSC data, nST4 had more C-S-H gel than the $\mathrm{CH}$ which was consumed through pozzolanic reaction. Although the compressive strength of nST3, nST5, and nST6 were lower than nST4, they remained higher than that of the neat oilwell cement sample, nST0. However, although the evolution of compressive strength for the ternary system was slightly lower than the nano- $\mathrm{SiO}_{2}$ systems, it was also slightly higher than that for nano- $\mathrm{TiO}_{2}$ binary systems. Nano- $\mathrm{SiO}_{2}$ can react with the $\mathrm{CH}$ from hydration to produce additional C-S-H gel while the fine particles of nano- $\mathrm{TiO}_{2}$ fill the pores between the produced $\mathrm{C}-\mathrm{S}-\mathrm{H}$ gel reducing the harmful pores and inhibiting further growth of $\mathrm{CH}$ and ettringite (Qing et al. 2007, Ren et al. 2018). Thus, it can be advantageous to use the ternary system for better strength evolution at least in hostile regions taking into consideration the economic factor.

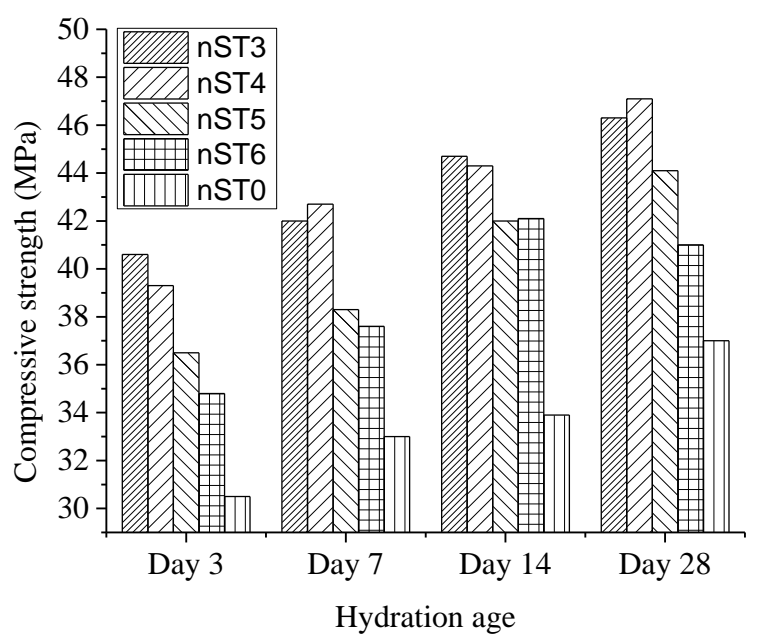

Figure 3: Compressive strengths for control and ternary systems.

\section{Wellbore shear bond strength evolution}

Figure 4 (a) presents the results of shearbond strengths for the studied samples with nano- $-\mathrm{SiO}_{2}$, whereas $\mathrm{nS0}$ is the reference sample of oilwell cement. All mix proportions of the cement design with and without nano$\mathrm{SiO}_{2}$ showed an increasing trend of shear-bond strength with hydration age. At 3 days of 
hydration age, samples made with nano- $\mathrm{SiO}_{2}$ showed higher strength evolution as compared to the control sample except for $\mathrm{nS} 4$ which displayed lower shear bond strength relative to nS0. An nS2 system showed high shear bond strength at all ages of cement hydration. Although $\mathrm{nS} 3$ was slightly lower than $\mathrm{nS} 2$ in shear bond strength evolution, it was consistently increasing with age. At the age of 28 days, $\mathrm{nS} 4$ displayed shear bond strength slightly lower than the control nS0. It is reported that more $\mathrm{CH}$ are found concentrated along with the cement-formation interface (Hao et al. 2016). These provide a weak bond between cement and the formation. Their hexagonal-platelet morphology can cause crack upon expansion due to growth adding to the weak bond and thus lower shear bond strength (Qing et al. 2007). Therefore, consumption of $\mathrm{CH}$ along the cement-formation interface and expansion of the hydrated structure are the possible means of increasing the bond strength (Al Khalaf and Page 1979, Hwang et al. 2018). The addition of nano- $\mathrm{SiO}_{2}$ helps to reduce the amount, size and inhibit the growth of $\mathrm{CH}$ through pozzolanic reaction and filler effect, respectively.

The effect of the nano- $\mathrm{TiO}_{2}$ binary system on the shear bond strength of oilwell cement is graphically presented in Figure 3 (b). The figure depicts that the shear bond strength of both neat oilwell cement and the binary system increased with curing age. At the age of 3 to 7 days of hydration, the nT3 system showed slightly higher shear bond strength evolution than the reference sample and the rest of the systems. Then, next to nT3, the nT2 system had also influenced the shear bond strength evolution with time. It can also be noted that different from the observation in the case of nano- $\mathrm{SiO}_{2}$, at the same age, the nT4 system had shear bond strength higher than that of the conventional oilwell cement sample. From the age of 14 to 28 days, although the nT2 system showed systematic progress, the nT3 system had more strength development at the age of 28 days. This shows that substitution of oilwell cement with $2-3 \%$ of nano- $\mathrm{TiO}_{2}$ gives the optimum dosage that influences more on the cement-formation bond evolution. The nT1 and nT4 systems had also linear increase with curing age, while at all ages were slightly higher than the reference oilwell cement sample. The influence of nano- $\mathrm{TiO}_{2}$ on strength evolution is attributable to its ability to promote the early hydration of cement while accelerating the formation and precipitation of hydration products (Nazari and Riahi 2011, Jalal et al. 2013, Ma et al. 2016).

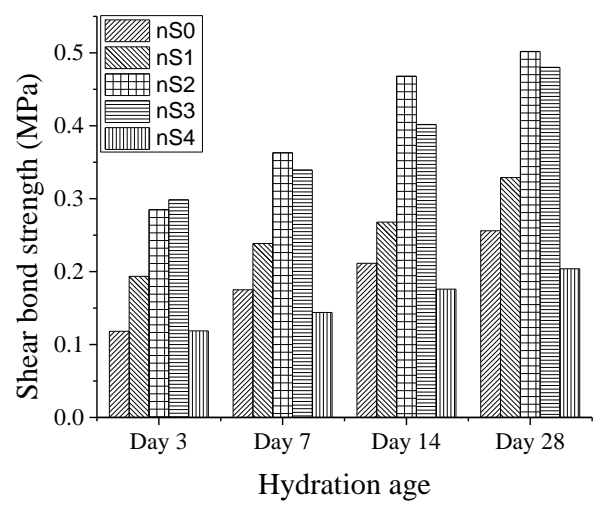

(a)

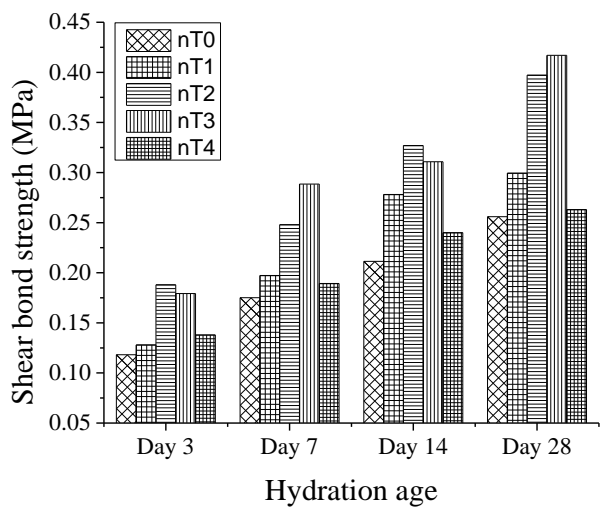

(b)

Figure 4: Shear-bond strengths for control, nano- $\mathrm{SiO}_{2}$, and nano- $\mathrm{TiO}_{2}$ binary systems. 
The reduction of $\mathrm{CH}$ crystals was more through the coupling of nano- $\mathrm{SiO}_{2}$ and nano$\mathrm{TiO}_{2}$. As can be observed from Figure 5, at 3 days, the shear bond strength increased by $110.6 \%$, and $55 \%$ at 28 days when compared with the results in Figure 4. An nST4 system showed higher shear bond strength both at early and late curing age than the rest of the ternary systems. The increase in shear bond strength for the ternary system is a combination of reasons. First is attributed to the ability to inhibit the growth of ettringite and $\mathrm{CH}$ crystals by filling the space and porosities in silicate gel. This provides no expansion space for the two crystals serving no room for cracks evolution while making dense adhesive cement structure (Ren et al. 2018). The other possible reason is the ability to act as nucleation sites for crystallization during hydration and thus accelerating the hydration process while giving to more products. The presence of nano- $\mathrm{SiO}_{2}$ serves more advantages by reacting with $\mathrm{CH}$ through pozzolanic reaction, reducing their amounts while adding more C-S-H gel in the cementitious system. The shear bond strength results showed that the nST3 and nST4 systems consumed most of the $\mathrm{CH}$ at the cement formation interface enhancing the evolution of the shear bond strength of the studied cementitious system. In this system, nT2 provided for nucleation sites during the early stage, while during the onset of the next stage, $\mathrm{nS} 2$ and $\mathrm{nS} 3$ offered the nucleation as well as the pozzolanic reaction (Stefanidou and Papayianni 2012, Ren et al. 2018).

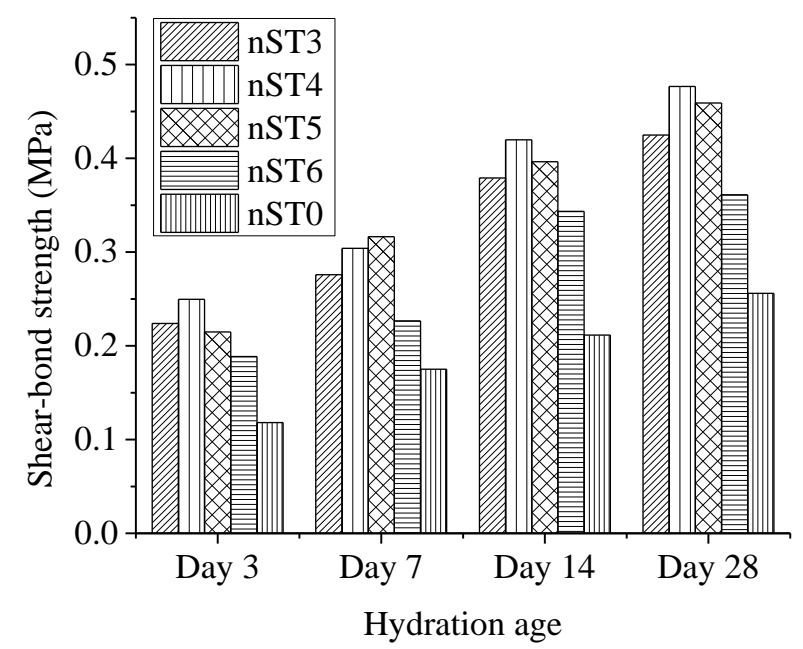

Figure 5: Shear-bond strengths for control and coupled nano- $\mathrm{SiO}_{2}$ and nano- $\mathrm{TiO}_{2}$ tertiary systems.

\section{XRD studies}

Figures 6-9 present the XRD patterns for the studied cement systems. The peak intensities represent $\mathrm{CH}$ crystals compared to silicates. Figure 6 displays the XRD patterns for the reference API class G oilwell cement, $\mathrm{nS} 0$, used during this study at the curing age of 28 days. The arrays demonstrate higher peak intensities with the primary peak at around $18^{\circ}$. It means that large percentages of $\mathrm{CH}$ are present in the cement system. This provides proof that hydration of cement had continued to this late period. Although not observed in the XRD data analysis, C-S-H gel adds more to the development of strength than $\mathrm{CH}$. As a consequence, their impact on mechanical strength is influenced by temperature and curing time from other influences.

As reported, elevating the temperature of the sample curing above $120{ }^{\circ} \mathrm{C}$ can 
compromise the development of the strength because of alterations in the phases of C-S-H (Souza et al. 2012, Bu et al. 2016). The patterns for the nano- $\mathrm{SiO}_{2}$ binary system are presented in Figure 7. The figure indicates that $\mathrm{nS} 2$ and $\mathrm{nS} 3$ had lower peak height than the reference sample, nS0. This gives evidence to the occurrence of the pozzolanic reaction to have taken place as to 28 days of hydration. The observation agrees in part with the high compressive and shear bond strength displayed by the samples in the binary system. Furthermore, nS4 showed high $\mathrm{CH}$ peak heights than $\mathrm{nS} 0$ at the age of 28 days. This means the addition of $\mathrm{nS} 4$ to the system did not offer enough in terms of pozzolanic reaction with the produced $\mathrm{CH}$. The noted contribution to the strength evolution might have come through the filling effect which aided to reduce the effect of $\mathrm{CH}$ and ettringite growth in the cement matrix.

Figure 8 presents patterns for samples made by replacing oilwell cement with nano- $\mathrm{TiO}_{2}$ at varied dosages. Different from nano- $\mathrm{SiO}_{2}$, the patterns show a higher peak height for $\mathrm{CH}$ than those of the reference sample. Previous studies such as Jalal et al. (2013) showed that the addition of nano- $\mathrm{TiO}_{2}$ up to $4 \%$ accelerates C$\mathrm{S}-\mathrm{H}$ gel formation due to increased crystalline $\mathrm{CH}$. This means, presence of nano- $\mathrm{TiO}_{2}$ in the cement system accelerates the rate of cement hydration through nucleation and thus lead to more hydration products. Therefore, the observed high peak heights of $\mathrm{CH}$ for this case mean nano- $\mathrm{TiO}_{2}$ aided the formation of $\mathrm{CH}$ at an early age and due to the filling effect into the $\mathrm{C}-\mathrm{S}-\mathrm{H}$ gel pores prevented the $\mathrm{CH}$ from causing harm to the strength evolution with hydration age.

The XRD patterns for nano- $\mathrm{SiO}_{2}$-nano $\mathrm{TiO}_{2}$ ternary systems are presented in Figure 9. It is substantiated that, the coupling of the nanoparticles increased the strength evolution with curing time. The amount of the coupled system also affected greatly the strength of the hardened cement. As indicated in Figure 9 (b), cement system nST4 displayed low peak heights for $\mathrm{CH}$ compared to the rest of the ternary systems. Also, as depicted in Figure 9 (d), the ternary system nST6 had the highest $\mathrm{CH}$ peaks. This observation means the nST4 system had better performance in terms of strength evolution. The observation concurs with the corresponding compressive strength evolution. This shows that at the age of 28 days nST4 consumed most of the $\mathrm{CH}$ in the cement system reducing their content due to the synergistic effect of the nanoparticles added and thus aiding strength evolution. Therefore, nST4 serves as the optimum cement replacement with the nanoparticles coupled system for better cementing. Moreover, lower peak heights of calcium silicates contribute to the evidence that hydration had proceeded and so the noted strength of the hydrated cement material.

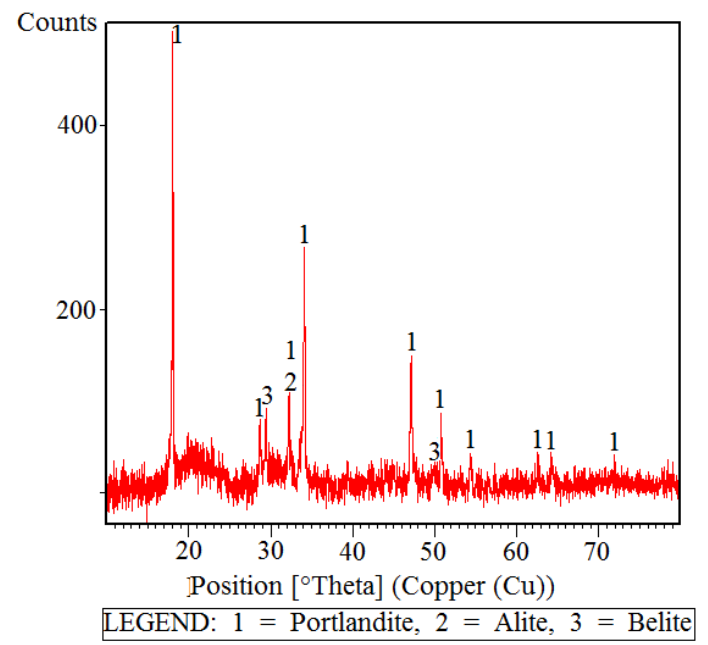

Figure 6: XRD patterns of neat oilwell cement sample, $\mathrm{nS} 0$. 
Mabeyo and $\mathrm{Gu}$ - Coupled effects of hydrophilic nano-SiO $\mathrm{S}_{2}$ and anatase nano-TiO $\mathrm{T}_{2} \ldots$
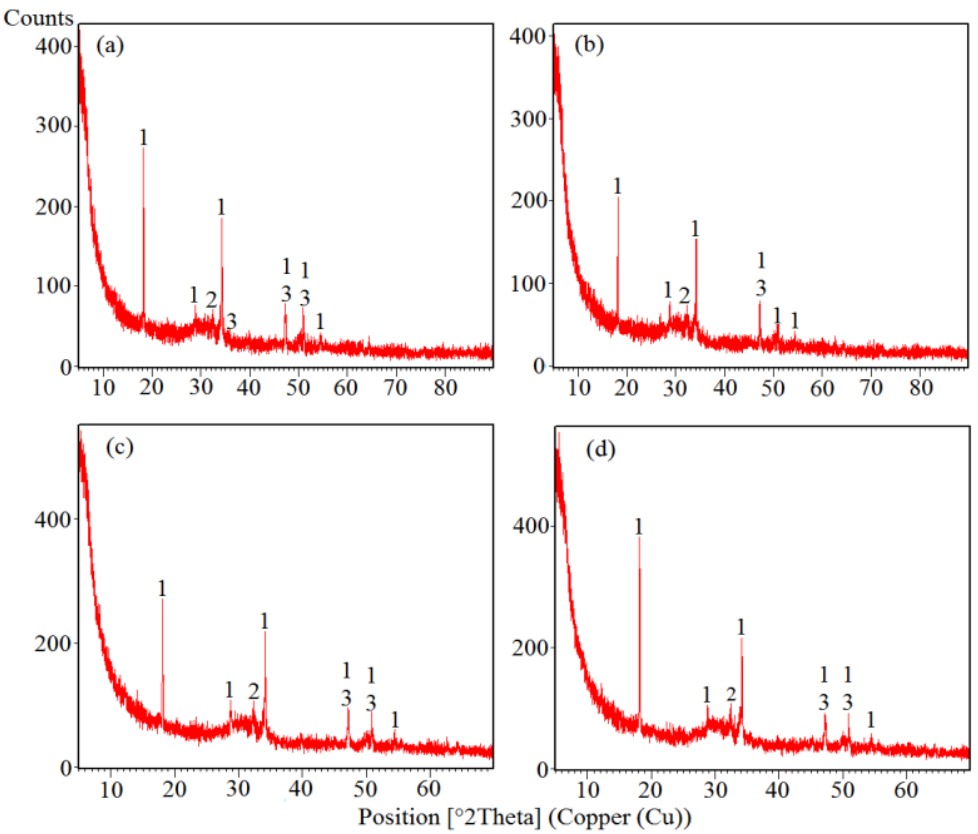

LEGEND: $1=$ Portlandite, $2=$ Alite, $3=$ Belite

Figure 7: XRD patterns for cement systems with different nano- $\mathrm{SiO}_{2}$ proportions: (a) $\mathrm{nS} 1$, (b) $\mathrm{nS} 2$, (c) $\mathrm{nS} 3$ and (d) $\mathrm{nS} 4$.
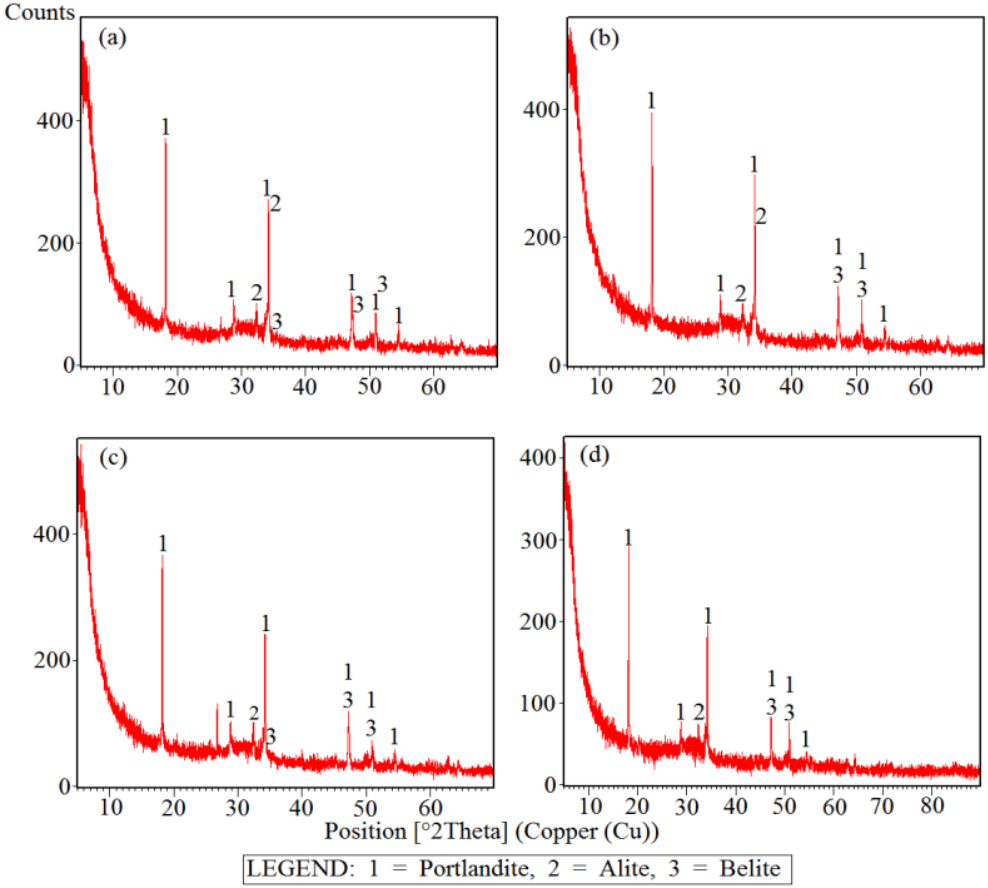

Figure 8: XRD patterns for cement systems with different nano- $\mathrm{TiO}_{2}$ proportions (a) nT1, (b) nT2, (c) nT3 and (d) nT4. 

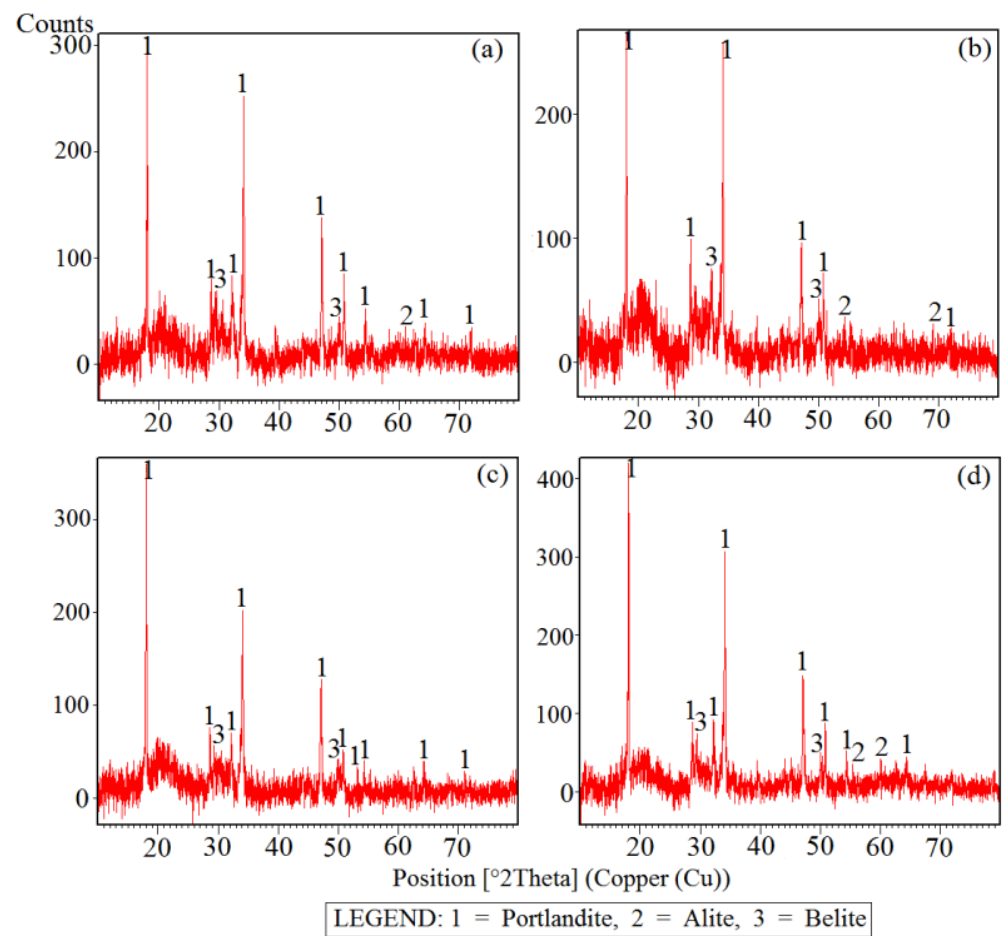

Figure 9: $\mathrm{XRD}$ patterns for nano- $\mathrm{SiO}_{2}$-nano- $\mathrm{TiO}_{2}$ ternary cement system: (a) nST3, (b) nST4, (c) nST5, and (d) nST6.

\section{TG and DSC studies}

Figure 10 (a) presents the TG curves for the neat oilwell cement sample (nS0), nS1, nT2, and nST3. From the curves, two major regions of mass loss can be identified. The first region from 30 to $305{ }^{\circ} \mathrm{C}$ presents the mass loss due to dehydration of $\mathrm{C}-\mathrm{S}-\mathrm{H}$, and the second region from $310{ }^{\circ} \mathrm{C}$ to around $600{ }^{\circ} \mathrm{C}$ in the region for mass loss due to decomposition of $\mathrm{CH}$ (Mabeyo et al. 2020). The measured mass loss for $\mathrm{nS} 0$ corresponding to $\mathrm{C}-\mathrm{S}-\mathrm{H}$ decomposition was $7.13 \%$, while that for $\mathrm{CH}$ is $11.75 \%$. These amounts increased and decreased, respectively compared to the binary and ternary systems. This means, supplementing oilwell cement with nanoparticles, increases the amount of C$\mathrm{S}-\mathrm{H}$ gel while decreasing the corresponding $\mathrm{CH}$. The observed mass changes due to dehydration of $\mathrm{C}-\mathrm{S}-\mathrm{H}$ for $\mathrm{nS} 1, \mathrm{nT} 2$, and $\mathrm{nST} 3$ were $7.15,8.65$, and $9.28 \%$, respectively. As can be seen, the coupled nanoparticles showed higher mass loss compared to the neat cement and the binary systems giving evidence to the advantage of coupling nanoparticles for better strength evolution. The corresponding mass losses due to $\mathrm{CH}$ decomposition for $\mathrm{nS} 1, \mathrm{nT} 2$, and $\mathrm{nST} 3$ were $7.69,5.78$, and $5.01 \%$. These values were lower compared to $11.75 \%$ for nS0. This means $\mathrm{nSO}$ has more $\mathrm{CH}$ than the binary and ternary systems. The reason attributable to the decreased amount of $\mathrm{CH}$ and increased C-S-H gel is due to the existence of a pozzolanic reaction that converts most of $\mathrm{CH}$ into secondary C-S-H gel for the binary and ternary systems. The results correspond with the XRD results which indicated high $\mathrm{CH}$ peak heights for $\mathrm{nS} 0$ as discussed in the previous section.

Figure 10 (b) presents the DSC results for selected nS0, nS1, nT2, and nST3 samples. Three endothermic peaks are obvious each presenting a specific feature for the decomposition of cement hydration products mainly $\mathrm{C}-\mathrm{S}-\mathrm{H}$ and $\mathrm{CH}$. At low temperatures, 
the endothermic peak below $200{ }^{\circ} \mathrm{C}$ is attributable to the dehydration of silicate hydrates. The peak intensity increases with the hydrate amounts. It can be observed that the peak increased with the addition of nanoparticles. Another important endothermic peak can be observed at $424.193{ }^{\circ} \mathrm{C}$. The intensity decreased with the addition of the nanoparticles giving evidence for the reduction

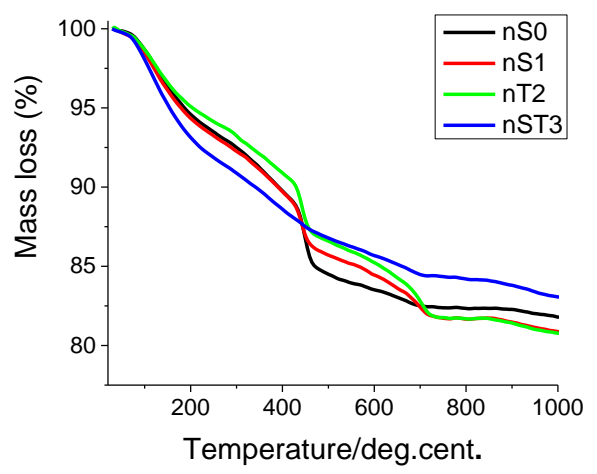

(a) of $\mathrm{CH}$ as are consumed through pozzolanic reaction adding to the strength evolution of the cement system. The third peak at about $709.193{ }^{\circ} \mathrm{C}$ represents the decomposition of calcites. From the figure, the peak value for the ternary system, nST3 decreased significantly proving the importance of the synergistic effects of the two nanoparticles.

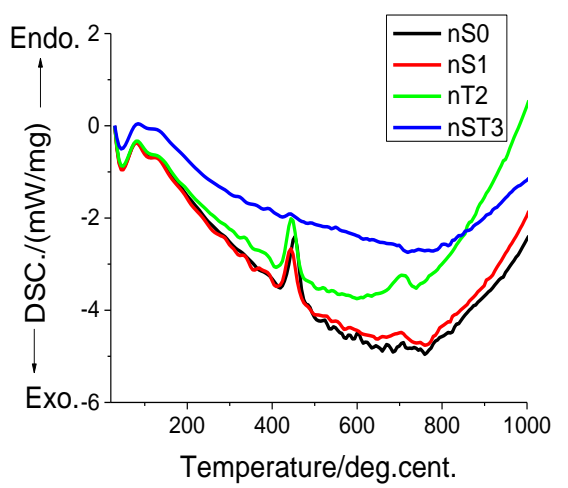

(b)

Figure 10: (a) TG curves, (b) DSC curves for nS0, nS1, nT2, and nST3.

\section{Conclusions}

The results obtained indicated that both nano- $\mathrm{SiO}_{2}$ and nano- $\mathrm{TiO}_{2}$ increase the compressive and shear bond strengths of the oilwell cement. There exist synergistic effects between nano- $\mathrm{SiO}_{2}$ and nano- $\mathrm{TiO}_{2}$ on cement strength evolution when coupled in the cement systems. The synergistic effect is more effective at the early age of cement hydration than it is at a later age. An increase beyond 4\% of the nanoparticles had strength decelerating effect, while $3 \%$ of the coupled system serves as the optimum amount for high strength evolution thus can help to overcome the load stresses which affect the normal oilwell cement. Further field studies are recommended to meet other varying subsurface conditions such as high pressures that are not covered in this study.

\section{Acknowledgments}

China Scholarship Council through China University of Geosciences (Wuhan) (Grant no;
CUGQYZX1710) and the National Natural Science Foundation of China (grant no. 41972326 and 51774258) are highly acknowledged for the financial support that helped to cover costs of study materials.

\section{References}

Al Khalaf MN and Page CL 1979 Steel/mortar interfaces: Microstructural features and mode of failure. Cem. Concr. Res. 9(2): 197-207.

API 10A 2002 Specification for Cements and materials for well cementing, $24^{\text {th }}$ ed, American Petroleum Institute, Washington D.C.

Beigi MH, Berenjian J, Lotfi Omran O, Sadeghi-Nik A and Nikbin IM 2013 An experimental survey on combined effects of fibers and nanosilica on the mechanical, rheological, and durability properties of self-compacting concrete. Mater. Des. 50: 1019-1029. 
Bera A and Belhaj H 2016 Application of nanotechnology by means of nanoparticles and nanodispersions in oil recovery - A comprehensive review. J. Nat. Gas Sci. Eng. 34: 1284-1309.

Bu Y, Du J, Guo S, Liu H and Huang C 2016 Properties of oil well cement with high dosage of metakaolin. Constr. Build. Mater. 112: 39-48.

Cestari AR, Vieira EFS, Silva ECS, Alves FJ and Andrade MAS 2013 Synthesis, characterization and hydration analysis of a novel epoxy/superplasticizer oilwell cement slurry-Some mechanistic features by solution microcalorimetry. J. Colloid Interface Sci. 392(1): 359-368.

de Paula JN, Calixto JM, Ladeira LO, Ludvig P, Souza TCC, Rocha JM and de Melo AAV 2014 Mechanical and rheological behavior of oil-well cement slurries produced with clinker containing carbon nanotubes. J. Pet. Sci. Eng. 122: 274-279.

de Sena Costa BL, de Souza GG, de Oliveira Freitas JC, da Silva Araujo RG and Santos PHS 2017 Silica content influence on cement compressive strength in wells subjected to steam injection. J. Pet. Sci. Eng. 158: 626-633.

El-Gamal SMA, Amin MS and Ramadan M 2017 Hydration characteristics and compressive strength of hardened cement pastes containing nano-metakaolin. $H B R C$ J. 13: 144-121.

Gu J, Zhong P, Shao C, Bai S, Zhang $\mathrm{H}$ and Li K 2012 Effect of interface defects on shear strength and fluid channeling at cementinterlayer interface. J. Pet. Sci. Eng. 100: 117-122.

Hao H, Gu J, Huang J, Wang Z, Wang Q, Zou Y and Wang W 2016 Comparative study on cementation of cement-mudcake interface with and without mud-cake-solidificationagents application in oil \& gas wells. J. Pet. Sci. Eng. 147: 143-153.

Hwang J, Ahmed R, Tale S and Shah S 2018 Shear bond strength of oil well cement in carbonic acid environment. J. $\mathrm{CO}_{2}$ Util. 27: 60-72.
Jadhav R, Rao Palla VG, Datta A and Dumbre M 2017 Effect of casing coating materials on shear-bond strength. Soc. Pet. Eng. SPE186441-MS: 1-6.

Jafariesfad N, Geiker MR, Gong Y, Skalle P, Zhang Z and He J 2017 Cement sheath modification using nanomaterials for longterm zonal isolation of oil wells: Review. $J$. Pet. Sci. Eng. 156: 662-672.

Jalal M, Fathi M and Farzad M 2013 Effects of fly ash and $\mathrm{TiO}_{2}$ nanoparticles on rheological, mechanical, microstructural and thermal properties of high strength selfcompacting concrete. Mech. Mater. 61: 1127.

Jimenez WC, Urdaneta JA, Pang X, Garzon JR, Nucci G and Arias H 2016 Innovation of annular sealants during the past decades and their direct relationship with on/offshore wellbore economics. Soc. Pet. Eng. SPE 180041-MS: 1-18.

Khoshakhlagh A, Nazari A and Khalaj G 2012 Effects of $\mathrm{Fe}_{2} \mathrm{O}_{3}$ nanoparticles on water permeability and strength assessments of high strength self-compacting concrete. $J$. Mater. Sci. Technol. 28(1): 73-82.

Lau HC, Yu M and Nguyen QP 2017 Nanotechnology for oilfield applications: Challenges and impact. J. Pet. Sci. Eng. 157: 1160-1169.

Lee BY, Jayapalan AR and Kurtis KE 2013 Effects of nano- $\mathrm{TiO}_{2}$ on properties of cement-based materials. Mag. Concr. Res. 65: 1293-1302.

Lee BY and Kurtis KE 2010 Influence of $\mathrm{TiO}_{2}$ nanoparticles on early $\mathrm{C}_{3} \mathrm{~S}$ hydration. $J$. Am. Ceram. Soc. 93(10): 3399-3405.

Li Z, Sun J, Luo PY, Lin L, Deng Z and Guo X 2017 Research on the law of mechanical damage-induced deformation of cement sheaths of a gas storage well. J. Nat. Gas Sci. Eng. 43: 48-57.

Ma B, Li H, Li X, Mei J and Lv Y 2016 Influence of nano- $\mathrm{TiO}_{2}$ on physical and hydration characteristics of fly ash-cement systems. Constr. Build. Mater. 122: 242253. 
Mabeyo and $\mathrm{Gu}$ - Coupled effects of hydrophilic nano-SiO${ }_{2}$ and anatase nano-TiO $\mathrm{T}_{2} \ldots$

Mabeyo PE, Ibrahim YS and Gu J 2020 Effect of high metakaolin content on compressive and shear-bond strengths of oil well cement at $80{ }^{\circ} \mathrm{C}$. Constr. Build. Mater. 240: 117962.

Nazari A and Riahi S 2011 The effects of $\mathrm{TiO}_{2}$ nanoparticles on physical, thermal and mechanical properties of concrete using ground granulated blast furnace slag as binder. Mater. Sci. Eng. A 528: 2085-2092.

Nazari A and Riahi S 2010 The effect of $\mathrm{TiO}_{2}$ nanoparticles on water permeability and thermal and mechanical properties of high strength self-compacting concrete. Mater. Sci. Eng. A 528(2): 756-763.

Omosebi O, Maheshwari H, Ahmed R. Shah S and Osisanya S 2017 Experimental study of the effects of $\mathrm{CO}_{2}$ concentration and pressure at elevated temperature on the mechanical integrity of oil and gas well cement. J. Nat. Gas Sci. Eng. 44, 299-313.

Qing Y, Zenan Z, Deyu K and Rongshen C 2007 Influence of nano- $\mathrm{SiO}_{2}$ addition on properties of hardened cement paste as compared with silica fume. Constr. Build. Mater. 21(3): 539-545.

Rai S and Tiwari S 2018 Nano silica in cement hydration. Mater. Today Proc. 5(3): 91969202.

Ren J, Lai Y and Gao J 2018 Exploring the influence of $\mathrm{SiO}_{2}$ and $\mathrm{TiO}_{2}$ nanoparticles on the mechanical properties of concrete. Constr. Build. Mater. 175: 277-285.

Sadeghi-Nik A, Berenjian J, Bahari A, Safaei AS and Dehestani M 2017 Modification of microstructure and mechanical properties of cement by nanoparticles through a sustainable development approach. Constr. Build. Mater. 155: 880-891.

Salehi S, Khattak MJ, Bwala AH and Karbalaei FS 2017 Characterization, morphology and shear bond strength analysis of geopolymers: Implications for oil and gas well cementing applications. J. Nat. Gas Sci. Eng. 38: 323-332.

Soares LWO, Braga RM, Freitas, JCO, Ventura RA, Pereira DSS and Melo DMA 2015 The effect of rice husk ash as pozzolan in addition to cement Portland class $\mathrm{G}$ for oil well cementing. J. Pet. Sci. Eng. 131: 8085.

Souza P, Soares R, Anjos M, Freitas J, Martinelli A and Melo D 2012 Cement Slurries of oil wells under high temperature and pressure: the effects of the use of ceramic waste and silica flour. Brazilian J. Pet. Gas 6(3): 105-113.

Stefanidou M and Papayianni I 2012 Influence of nano- $\mathrm{SiO}_{2}$ on the Portland cement pastes. Compos. Part B Eng. 43(6): 2706-2710.

Tzileroglou C, Stefanidou M, Kassavetis S and Logothetidis S 2017 Nanocarbon materials for nanocomposite cement mortars. Mater. Today Proc. 4(7): 6938-6947.

Won J, Lee D, Na K, Lee IM and Choi H 2015 Physical properties of G-class cement for geothermal well cementing in South Korea. Renew. Energy 80: 123-131.

$\mathrm{Xu} \mathrm{B}$, Yuan B, Wang Y, Zeng S and Yang Y 2019 Nanosilica-latex reduction carbonation-induced degradation in cement of $\mathrm{CO}_{2}$ geological storage wells. J. Nat. Gas Sci. Eng. 65: 237-247.

Zeng Y, Liu R, Li X, Zhou S, Tao Q and Lu P 2019 Cement sheath sealing integrity evaluation under cyclic loading using largescale sealing evaluation equipment for complex subsurface settings. J. Pet. Sci. Eng. 176: 811-820. 